\title{
Perancangan Prototipe Aplikasi Customer Relationship Management (CRM) Berbasis SMS Gateway Untuk Mendukung Proses Penyetaraan Mahasiswa Pada Universitas Budi Luhur
}

\author{
Nofiyani' ${ }^{1}$, Yesi Puspita Dewi ${ }^{2}$ \\ Universitas Budi Luhur \\ Jl. Ciledug Raya, Petukangan Utara, Jakarta Selatan \\ nofiyani@budiluhur.ac.id ${ }^{1}$,yesi.puspitadewi@budiluhur.ac.id ${ }^{2}$
}

\begin{abstract}
The company began to aware potential sectors that could maintain and even increase revenue. So that, staying in touch with customers become serious point at Budi Luhur University, which is one of the private universities in Jakarta. Therefore various efforts made so that customer has good relations with the company. The solution is providing easy access to information using communication devices in the form of mobile phones, especially in the process of "penyetaraan mahasiswa". Writer applies the Customer Relationship Management (CRM) approach which aims to convey information to customers more efficiently by using communication devices. The design of the system is based on the SMS gateway that become bridge between handphone and the SMS server. Based on the research methodology, the design of an SMS gateway-based system is obtained, so that it can help simplify and speed up the delivery of information about the timeline and checkpoint progress of "penyetaraan mahasiswa".
\end{abstract}

Keywords: Customer Relationship Management (CRM), Handphone, Short Message Service, SMS gateway

Abstrak- Perusahaan mulai memperhatikan sektor potensial yang dapat mempertahankan bahkan meningkatkan pendapatan, sehingga kepentingan untuk tetap berkomunikasi dengan pelanggan menjadi salah satu perhatian utama. Hal ini diterapkan pada Universitas Budi Luhur yang merupakan salah satu universitas swasta di Jakarta. Karenanya berbagai upaya dilakukan agar hubungan pelanggan dengan perusahaan terjalin dengan baik. Salah satunya adalah dengan memberikan kemudahan mendapatkan informasi menggunakan perangkat komunikasi berupa telepon genggam, khususnya pada proses penyetaraan mahasiswa. Dalam menyelesaikan persoalan tersebut, penulis menerapkan pendekatan Customer Relationship Management (CRM) yang bertujuan menyampaikan informasi kepada pelanggan dengan lebih efisien dengan menggunakan perangkat komunikasi. Pengembangan rancang bangun sistem berbasis SMS gateway yang menjadi jembatan antara handphone dengan sistem yang menjadi server dengan SMS sebagai informasinya. Berdasarkan metodologi penelitian yang telah disusun, didapatkan sebuah rancangan prototype aplikasi berbasis SMS gateway yang sesuai, sehingga dapat membantu mempermudah dan mempercepat penyampaian informasi mengenai timeline dan checkpoint progress penyetaraan.

Kata kunci: Customer Relationship Management (CRM), Handphone, Short Message Service, SMS gateway

\section{PENDAHULUAN}

Aplikasi Customer Relationship Management Untuk Proses Penyetaraan Mahasiswa (Nofiyani)| 54 
Perusahaan tidak lagi hanya memikirkan keuntungan semata tetapi mulai memperhatikan sektor potensial yang dapat mempertahankan atau meningkatkan pendapatan sehingga kepentingan pelanggan menjadi perhatian utama. Karenanya berbagai upaya dilakukan agar hubungan pelanggan dengan perusahaan berjalan dengan baik [4]. Customer Relationship Management (CRM) merupakan suatu sistem yang dikembangkan dengan tujuan untuk menunjang perusahaan membangun hubungan yang erat dengan para pelanggannya [9]. Berbagai macam perangkat komunikasi di Indonesia saat ini berkembang semakin canggih dalam kehidupan masyarakat dan tidak dapat dihindarkan. Seperti bertambah banyaknya masyarakat yang menggunakan perangkat komunikasi berupa telepon genggam. Hampir semua kegiatan manusia saat ini memang membutuhkan telepon genggam untuk digunakan sebagai alat komunikasi yang paling berguna dan efisien [8].

Proses penyetaraan mahasiswa di Universitas Budi Luhur masih dilakukan secara manual, tanpa menggunakan sistem informasi. Setelah mahasiswa menyerahkan berkas penyetaraan kepada petugas penyetaraan, diperlukan waktu seminggu untuk diproses oleh kampus. Proses tersebut terkadang melebihi waktu seminggu karena berbagai hal, keterlambatan ini terkadang tidak dapat diinformasikan kepada mahasiswa. Hal ini meyebabkan mahasiswa yang datang ke kampus untuk mengambil hasil penyetaraan melakukan komplain. Pada penelitian ini dibuat sebuah prototipe sistem Customer Relationship Management (CRM) yang dapat mengorganisasi proses penyetaraan mahasiswa dan mempermudah mahasiswa selaku customer mendapatkan informasi mengenai timeline dan checkpoint progress penyetaraan. Perancangan prototipe sistem CRM yang digunakan pada penelitian ini menggunakan perangkat komunikasi berupa aplikasi CRM berbasis SMS Gateway.

\section{METODOLOGI PENELITIAN}

Metodologi yang digunakan dalam penelitian ini adalah Model Waterfall. Model ini merupakan sebuah pendekatan terhadap pengembangan perangkat lunak yang sistematik, dengan beberapa tahapan, yaitu: System Engineering, Analysis, Design, Coding, Testing dan Implementation/Maintenance. Pemodelan sistem menggunakan UML (Unified Modeling Language).

\subsection{Metode Pemilihan Sample}

Metode pemilihan sample dilakukan dengan melakukan wawancara dengan key person, yaitu staf yang menangani penyetaraan.

\subsection{Metode Pengumpulan Data}

Data dan informasi yang diperoleh pada penelitian ini berasal dari data primer dan data sekunder. Pengumpulan data primer, peneliti menggunakan teknik pengumpulan data berikut ini:

a. Wawancara

Wawancara yang dilakukan dengan key person yaitu staf penyetaraan yang ada di Biro Administrasi Akademik \& Kemahasiswaan (BAAK), dengan tujuan mendapatkan gambaran kondisi yang ada, kebutuhan sistem, serta kondisi yang diharapkan. 
b. Observasi Lapangan

Observasi lapangan dilakukan dengan metode pengumpulan data yang digunakan untuk menghimpun data penelitian melalui pengamatan. Peneliti mengamati bagaimana proses penyetaraan mahasiswa dan mengumpulkan data-data yang berkaitan dengan penelitian ini.

c. Studi Literatur

Untuk menunjang penelitian, studi literatur dalam penelitian ini dilakukan dengan studi pustaka dari literatur yang bersumber pada publikasi penelitian berupa jurnal maupun paper, dan sumber-sember pada media internet

\subsection{Studi Literatur}

Tinjauan studi yang dijadikan acuan dalam melakukan penelitian ini mengacu pada beberapa penelitian terkait yang telah dilakukan sebelumnya yaitu sebagai berikut:

a. Jesica Mikha Pendey, Brata Wibawa Djojo \& Yulius pada tahun 2015 membuat penelitian "Analisis dan Perancangan Aplikasi SMS Gateway Untuk Meningkatkan Kualitas Pelayanan Pada PT. PLN (Persero) Wilayah Suluttenggo Kota Manado". Pada penelitian ini dibagung sebuah sistem e-CRM dengan SMS Gateway sehingga PLN dapat menyampaikan informasi pemadaman listrik kepada masyarakat dengan mudah [6]

b. Galih Pamungkas \& Galih Ryadi pada tahun 2015 membuat penelitian "Implementasi (CRM) Costumer Relationship Management Untuk Layanan Tamu di Kecamatan Berbah Sleman Yogyakarta". Pada penelitian ini dibangun sebuah sistem e-CRM dengan SMS Gateway sehingga pihak kecamatan dan tokoh masyarakat dapat memonitor keberadaan tamu dan memberikan pelayanan yang baik [5]

c. Madison \& Angga Pramudia pada tahun 2015 membuat penelitian "Perancangan dan Pembuatan Aplikasi Customer Relationship Management Pada Koperasi Pembangunan Usaha Sumbar Berbasis Web". Dengan penelitian ini bisa diketahui kepuasan pelanggan terhadap kinerja koperasi dan dapat digunakan sebagai sarana penunjang keputusan [3]

d. Sandy Kosasi pada tahun 2015 membuat penelitian "Perancangan Sistem Electronic Customer Relationship Management Untuk Mempertahankan Loyalitas Pelanggan". Pada penelitian ini dibangun sebuah aplikasi berbasis web dengan bahasa pemrograman PHP \& MySQL menggunakan metode RAD (Rapid Application Development) sehingga customer dengan mudah bisa mendapatkan informasi mengenai bisnis perusahaan dan perusahaan dapat dengan mudah berkomunikasi dengan pelanggan [1]

e. Margret Ade Cipta Rahmani, Haryono \& Eko Purwanti pada 2017 membuat penelitian menganai "Pengembangan Media Komunikasi Buku Penghubung Berbasis SMS Gateway dan Mobile Web". Pada penelitian ini dibangun aplikasi mobile web yang dilengkapi dengan SMS gateway sehingga memudahkan komunikasi antara pihak sekolah dan orangtua siswa [7]

f. Rudi Lesmana pada tahun 2017 membuat penelitian "Sistem Pelayanan Jasa Servis Motor Berbasis SMS Gateway Dengan Menerapkan Metode CRM (Studi Kasus Bengkel AHASS As Putra Motor)". Pada penelitian ini dibangun sebuah 
sistem berbasis web yang dilengkapi dengan SMS gateway sehingga pelanggan dapat melakukan booking service motor dengan mudah dan memberikan rating terhadap pelayanan bengkel [2]

Penelitian - penelitian diatas memiliki tujuan yang sama dengan penelitian ini yaitu melakukan peningkatan pelayanan untuk customer. Dari penelitian yang telah dilakukan sebelumnya didapatkan bahwa CRM dengan sms gateway dapat meningkatkan pelayanan karena mempermudah komunikasi antara perusahaan dan customer.

\section{HASIL DAN PEMBAHASAN}

\subsection{Fitur CRM}

Penjelasan mengenai fitur CRM yang diusulkan dan dirancang untuk Universitas Budi Luhur yang terdiri dari 3 fase Acquire, Enhance, dan Retain, antara lain :

a. Fase Acquire

Di dalam fase Acquire ini bertujuan untuk memenuhi kebutuhan petugas dan mahasiswa dalam proses penyetaraan di Universitas Budi Luhur.

b. Fase enhance

Fase ini memiliki fitur-fitur didalamnya yang bertujuan untuk menjalin hubungan dengan mahasiswa melalui pemberian pelayanan yang baik terhadap mahasiswanya disesuaikan dengan kebutuhan mahasiswa dan petugas sehingga dapat memberikan nilai tambah di mata mahasiswa.

c. Fase retain

Pada fase ini bertujuan untuk membantu Universitas Budiluhur dalam usaha untuk mengurangi komplain dari mahasiswa.

\subsection{Analisa Prototype Aplikasi Usulan}

Aplikasi Customer Relationship Management (CRM) Berbasis SMS Gateway merupakan aplikasi yang dibangun untuk mengotomasi distribusi informasi kepada mahasiswa ketika penyetaraan dinyatakan selesai prosesnya oleh petugas, sehingga informasi dapat dikirim dengan waktu yang cepat.

Sistem aplikasi berbasis SMS Gateway ini dijalankan pada sebuah komputer yang sudah diinstall aplikasi SMS Gateway yang terhubung dengan database dan menggunakan sebuah handphone yang dipasangkan pada port USB komputer sebagai terminal, dimana alat ini akan berfungsi untuk menerima pesan untuk mengirimkan SMS secara otomatis. Aplikasi ini akan berjalan setelah petugas mengubah status penyetaraan mahasiswa yang telah selesai diproses, sehingga petugas tidak perlu lagi mencari data dan menghubungi mahasiswa yang telah selesai proses penyetaraannya satu-per-satu. 


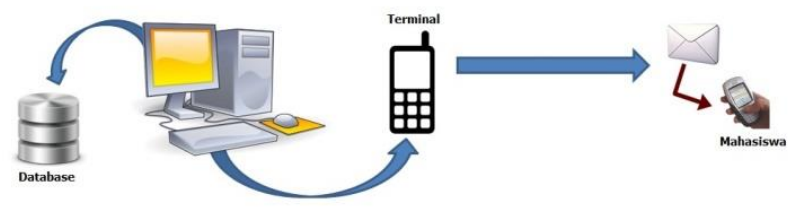

Gambar 1. Skema Pengiriman SMS

\subsection{Perancangan Sistem}

\subsubsection{Class Diagram}

Rancangan database yang diperoleh dari pengamatan proses bisnis ditampilkan dalam bentuk Class Diagram berikut:

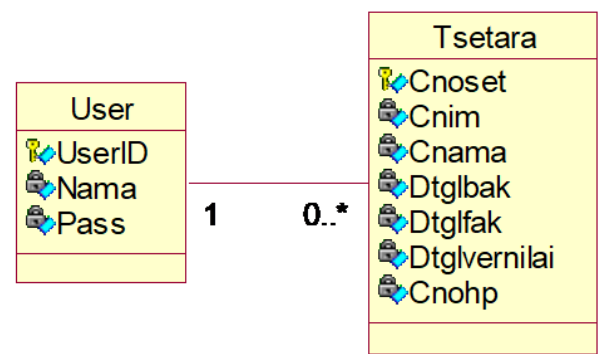

Gambar 2. Class Diagram

\subsubsection{Sequence Diagram}

Pada Sequence Diagram ini menggambarkan bagaimana objek berinteraksi dengan satu sama lain melalui pesan pada sekuensi sebuah use case atau operasi.

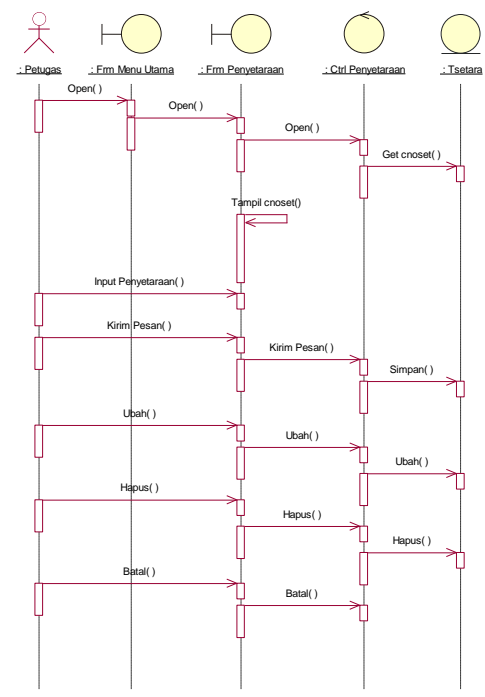

Gambar 3. Sequence Diagram 


\subsubsection{Rancangan Basis Data}

Pada langkah ini meliputi pembuatan indeks pada tabel dan membuat kelompo dari beberapa table. Proses perancangan fisik merupakan transformasi dari perancangan logis terhadap jenis DBMS yang digunakan sehingga dapat disimpan secara fisik pada media penyimpanan.

Tabel 1. Spesifikasi File User

\begin{tabular}{|l|l|c|c|}
\hline No. & Nama Field & Jenis & Lebar \\
\hline 1. & UserId & Text & 10 \\
2. & Nama & Text & 30 \\
3. & Pass & Text & 12 \\
\hline
\end{tabular}

Tabel 2. Spesifikasi File Tsetara

\begin{tabular}{|l|l|c|c|}
\hline No. & Nama Field & Jenis & Lebar \\
\hline 1. & Cnoset & Text & 10 \\
2. & Cnim & Text & 10 \\
3. & Cnama & Text & 50 \\
4. & Dtglbak & Date & 10 \\
5. & Dtglfak & Date & 10 \\
9. & Dtglvernilai & Date & 10 \\
10. & Cnohp & Text & 20 \\
\hline
\end{tabular}

\subsubsection{Rancangan Layar}

User interface merupakan bagian penting pada suatu aplikasi, karena bagian ini yang akan menjembatani pengguna dengan system. Desain user interface yang baik akan memudahkan pengguna dalam menggunakan aplikasi yang dibangun.

a. Tampilan Login

Dalam perancangan sistem baru, tetap harus diutamakan mengenai keamanan sistem. Hal ini untuk menghindari hal-hal yang tidak diinginkan seperti pencurian data dan lain sebagainya. Berikut tampilan login sebagai security atau pengaman sistem sebagai pintu masuk.

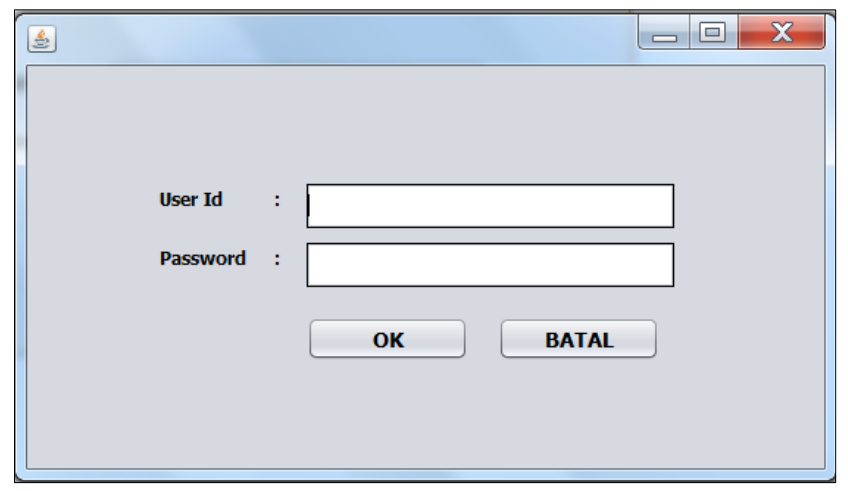

Gambar 4. Tampilan login

b. Tampilan Menu Utama

Setelah melewati form login maka username maupun password dinyatakan valid, selanjutnya masuk kedalam menu utama. Berikut tampilan menu utama : 


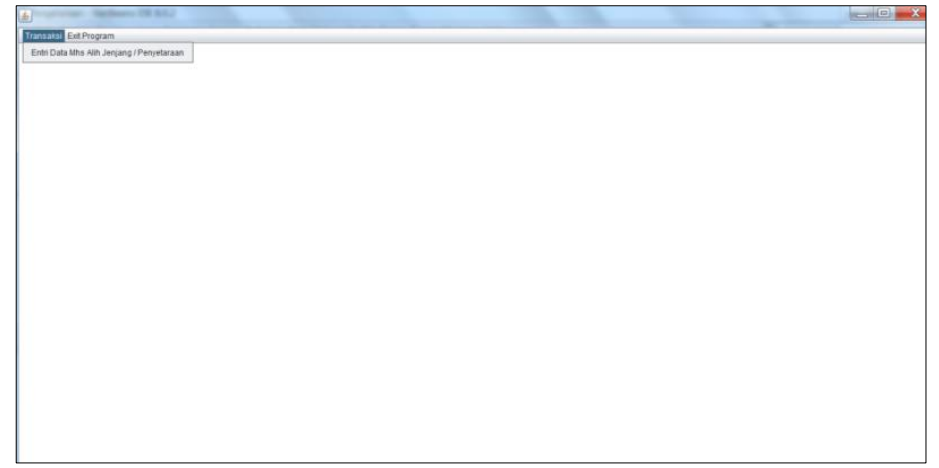

Gambar 5. Menu Utama

c. Tampilan Form Entry Data Mhs Alih Jenjang / Penyetaraan

Form ini digunakan untuk menginput data mahasiswa penyetaraan yang dinyatakan selesai prosesnya oleh petugas yang selanjutnya akan dikirimkan informasi kepada mahasiswa.

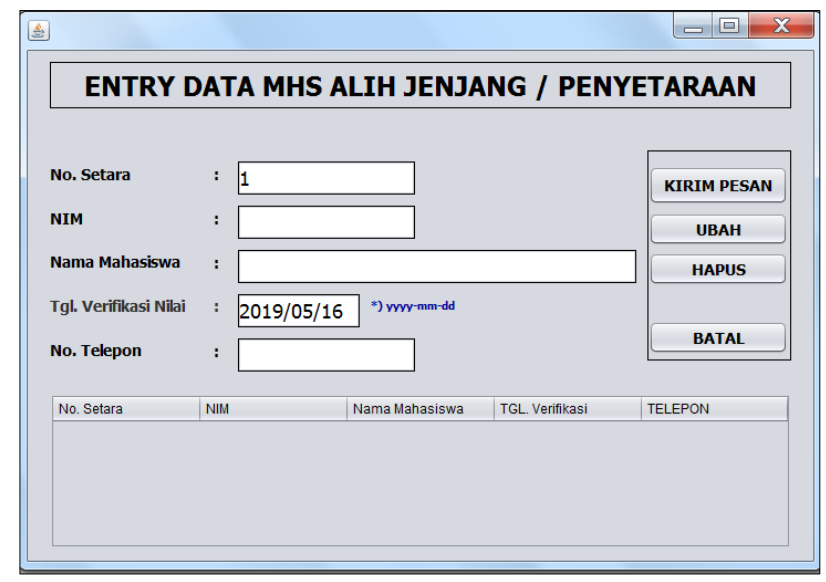

Gambar 5. Tampilan Form Entry Data Mhs Alih Jenjang / Penyetaraan

\section{KESIMPULAN}

Penulis menyampaikan kesimpulan dari penelitian ini berdasarkan uraian pada bab sebelumnya. Kesimpulan yang dapat ditarik oleh penulis adalah sebagai berikut.

a. Rancangan prototype aplikasi CRM yang dibuat sesuai dengan harapan dari petugas penyetaraan dan dapat membantu pekerjaan petugas tersebut.

b. Rancangan prototype aplikasi CRM mempermudah dan mempercepat penyampaian informasi mengenai timeline dan checkpoint progress penyetaraan kepada mahasiswa yang melakukan penyetaraan.

c. Rancangan prototype aplikasi CRM yang dibuat dapat mengurangi potensi komplain dari mahasiswa karena selesainya proses penyetaraan tidak sesuai dengan perkiraan waktu yang telah diinformasikan oleh petugas penyetaraan.

Setelah melakukan evaluasi pada penelitian ini, penulis mengumpulkan beberapa saran sebagai pertimbangan untuk pengembangan pada penelitian selanjutnya, antara lain: 
a. Rancangan prototype aplikasi dapat terintegrasi dengan system lain sehingga menjadi satu kesatuan system.

b. Rancangan prototype aplikasi memiliki fitur yang dapat terhubung dengan cloud storage sehingga terdapat history yang dapat tersimpan dan dapat diakses lagi kemudian.

c. Rancangan prototype aplikasi memiliki report yang menampilkan summary aktivitas penyetaraan.

\section{DAFTAR PUSTAKA}

[1] Kosasi, Sandy. 2015. Perancangan Sistem Electronic Customer Relationship Management Untuk Mempertahankan Loyalitas Pelanggan. STMIK Pontianak.

[2] Lesmana, Rudi. 2017. Sistem Pelayanan Jasa Servis Motor Berbasis SMS Gateway Dengan Menerapkan Metode CRM (Studi Kasus Bengkel AHASS As Putra Motor). Universitas Kuningan.

[3] Madison. Pamudia, Angga. 2015. Perancangan dan Pembuatan Aplikasi Customer Relationship Management Pada Koperasi Pembangunan Usaha Sumbar Berbasis Web. Universitas Putra Indonesia YPTK Padang.

[4] Nofiyani. 2016. Pengembangan Sistem Penunjang Keputusan Berbasis Web Untuk Menentukan Best Customers Dengan Model RFM (Recency, Frequency Dan Monetary), Metode Comparative Performance Index Dan Algoritma Single Linkage: Studi Kasus CV. XYZ. Universitas Budi Luhur.

[5] Pamungkas, Galih. Ryadi, Galih. 2015. Implementasi (CRM) Custumer Relationship Management Untuk Layanan Tamu di Kecamatan Berbah Sleman Yogyakarta. Universitas Ahmad Dahlan.

[6] Pendey, Jesica. Djojo, Brata. Yulius. 2015. Analisis dan Perancangan Aplikasi SMS Gateway Untuk Meningkatkan Kualitas Pelayanan Pada PT. PLN (Persero) Wilayah Suluttenggo Kota Manado. Universitas Bina Nusantara.

[7] Rahmani, Margret. Purwanti, Eko. Haryono. 2017. Pengembangan Media Komunikasi Buku Penghubung Berbasis SMS Gateway dan Mobile Web. Universitas Negri Semarang.

[8] Rustam, Muhammad. 2015. Survei Penggunaan Telepon Genggam Pada Masyarakat Nelayan Di Kecamatan Pulau Dullah Utara, Kota Tual Provinsi Maluku. 2015. Jurnal Penelitian Pers dan Komunikasi Pembangunan Vol. 19 No.1 Juni 2015: 11-22

[9] Setiawan, Dwianto. Saputra, Erik Hadi. 2015. Penerapan Konsep Customer Relationship Management (CRM) Berbasis Website pada UD Toyoriz Busindo. Jurnal Ilmiah DASI Vol. 16 No.1 Maret 2015: 34-39 